\title{
Planning of Optimal Capacity for the Middle-Sized Storage Using a Mathematical Model
}

https://doi.org/10.1515/eng-2019-0077

Received Sep 19, 2019; accepted Oct 02, 2019

\begin{abstract}
The article deals with the issue of midsize businesses, their position within the association, and specifically determining the size and range of stocks in their warehouses. A mathematical model is used and several examples explain the issue of calculating warehouse items.
\end{abstract}

Keywords: midsize business, store-house, replacement part, mathematical model

\section{Introduction}

Due to the ongoing globalisation especially small and midsize companies are affected by the immense pressure to reduce cost wherever they can. Nowadays almost no owner of a mid-size company could afford to spend more invest in stocking spare parts as minimum required in order not to endanger the production flow [1]. According to the view of the interviewed entrepreneurs, this difficult task was named as one of the major challenges they face in optimising their warehouse business. One common problem here is very often a lack of knowledge which spare parts or raw material in which quantity is important to stock and which sort of material does not necessarily needed to be stocked.

\footnotetext{
^Corresponding Author: Jozef Kul'ka: Technical University of Kosice, Faculty of Mechanical Engineering, Department of Design and Transport Engineering, Letna 9, 04200 Kosice; Slovakia; Email: jozef.kulka@tuke.sk

Martin Mantič: Technical University of Kosice, Faculty of Mechanical Engineering, Department of Design and Transport Engineering, Letna 9, 04200 Kosice; Slovakia; Email: martin.mantic@tuke.sk Melichar Kopas: Technical University of Kosice, Faculty of Mechanical Engineering, Department of Design and Transport Engineering, Letna 9, 04200 Kosice; Slovakia; Email: melichar.kopas@tuke.sk Eva Faltinová: Technical University of Kosice, Faculty of Mechanical Engineering, Department of Design and Transport Engineering, Letna 9, 04200 Kosice; Slovakia; Email: eva.faltinova@tuke.sk Marián Siman: Technical University of Kosice, Faculty of Mechanical Engineering, Department of Design and Transport Engineering, Letna 9, 04200 Kosice; Slovakia; Email: marian.siman@tuke.sk
}

According to the interviewed companies the entrepreneurs mainly report the following problems:

1. Stocking is difficult to calculate and often done by employees without transparency for the management.

2. Lack of modern stock calculation methods [2-4].

Providing a solution for these difficulties is not easy due to the fact that they all have various and different parameters just as size, geographic, industry sector etc [5]. Certainly there are many expensive tools and products to streamline the set up of warehouses available on the market. However for those of the companies who could not afford or are incapable to incorporate they could make use of the help of a mathematical approach model which is capable to identify the optimised amount of spare parts on basis of key driving parameters tailored to each of the individual circumstances [6]. This provisioning model is used successfully in the Aviation industry and prevents Airlines to run out of spare parts which could course an expensive downtime of one or more aircrafts. As spare parts in the aviation industry are mostly very expensive a lot of efforts have been done to find a model which guaranties that the right spare parts are available whenever they are immediately needed. With a few modifications on this model, it can be adapted to the individual needs of mid-size companies regardless their business and specification. Companies who have to run production machineries all have one thing in common. They must avoid a situation where there production flow is stopped due to a shortage or unavailability of the needed spare part. On the other hand they have the pressure not to over stock and invest too much on potential unused spare parts. To cope with these complex requirements the use of an adjusted mathematical approach model seems to be promising solution [7-9].

\section{The Mathematic Model Approach}

The aim of the usage of the mathematic model is to find out which items/ spare parts and quantities should be stocked by taking into account the individual circumstances of the 
user's warehouse. With this mathematic model it can be determined which items are essential to stock in order not to risk a potential production stop caused by a no stock situation. This model also allows to individual choose the most suitable protection level for different items. (Depending on their importance for the ongoing production flow) The further aim is to analysis and quantify the expected demand of items to be stocked by using mathematic principles to obtain the most efficient quantity and therefore minimising the investment in stockings. This model should be used for both:

1. Inventory of products or raw material

2. Inventory of spare parts needed to maintain the production machines.

The following examples demonstrate the calculation of spares parts by using the mathematic model. The used parameters can be modified and adjusted as required to the individual prerequisites.

The aim of the first calculation is to generically find out whether a spare should be stocked by analysis the risk of failure via testing the expected annual demand (Dann) against the minimum annual demand (MAD). If (Dann) $\geq$ MAD the first spare part should be allocated to the stock. The risk of out of stock during the re-supply chain delay could be mitigated by adding extra spares to obtain better protection in line with the expected demand (Drst) during the re-supply time.

Annual Demand:

$$
D_{a n n}=\frac{U H \times Q M \times Q P M}{M T B U R}
$$

Expected demand during Re-Supply Time Expendables:

$$
D_{r s t}=\frac{D_{a n n}}{1+M R F} \times\left(\frac{L T M+A T}{365}\right)
$$

Rotable / Repairable:

$$
\begin{aligned}
D_{r s t} & =\frac{D_{a n n}}{1+M R F} \times\left[\left(\frac{M S T \times T T}{365}\right)\right. \\
& \left.\times\left(1-\frac{S C R}{100}\right)+\left(\frac{S C R}{1000}\right) \times\left(\frac{L T M+A T}{365}\right)\right]
\end{aligned}
$$

Warehouse Parameters:

$$
\begin{aligned}
& \text { AT - Administration Time } \\
& \text { MRF - Machine Redundancy Factor } \\
& \text { UH - Usage Hours per Machine per Year } \\
& \text { MAD - Minimum Annual Demand } \\
& \text { QM - Quantity of Machine in usage } \\
& \text { TT - Transit Time. }
\end{aligned}
$$

Part and machine specific items:

QPM - Part quantity per machine

SCR - Scrap rate

LTM - Lead time

MST - Max/Mean shop processing time

TAT - Turn-Around time

MTBUR - Mean time between unscheduled removals

Additional variables used:

$\mathrm{D}_{a n n}$ - Annual Demand,

$\mathrm{D}_{r s t}$ - Expected demand during re-supply time,

$\mathrm{m}$ - Recommended quantity,

PL - Spares Protection level (may vary between $80 \%$ and $90 \%$ and may be selected as a function of the essentiality. For example category 1 spare part means the machine cannot run without this spare part and category $\mathbf{2}$ classifies spare parts which are needed but could not turn out to stop production),

CRF - Customised Redundancy Factor - can vary from 0.0 to $1.0(0 \%$ to $100 \%)$ with category 2 parts when $n>1$. Capture the amount of system redundancy the company owner intends to consider in his planning

$\mathrm{CRF}=0$ for category 1 spare parts.

\section{Poisson Distribution Table}

Recommend quantities (m) and Protection Levels (PL) have to be assessed assuming a Poisson distribution of spare part failure across time. In a Poisson process $m$ cannot be calculated straightforwardly. It requires an iterative process of assuming $\mathrm{m}$ testing it against the PL requirement and incrementing $\mathrm{m}$ to test it again, etc.

The Dann versus MAD test is needed to find out whether a spare part is qualified for stocking or not. Then the formula describes the probability to have never more removals than spare parts on stock during the re-supply time.

\section{Application of the Poisson Distribution Formula on Concrete Examples}

Example 1: Spare part category 1, $\mathrm{MAD}=1 ; \mathrm{D}_{a n n}=0.5$ Dann $<$ MAD - Spare part does not qualify as stocking spare part $\Rightarrow \mathrm{m}=0$.

Probability of failure is considered to low! 
Estimated Demand ( $\left.\mathrm{D}_{\mathrm{rst}}\right)$

\begin{tabular}{|c|c|c|c|c|c|c|c|c|c|c|c|}
\hline $\mathrm{m}$ & 1.0 & (1.1) & 1.2 & 1.3 & 1.4 & 1.5 & 1.6 & 1.7 & 1.8 & 1.9 & 2.0 \\
\hline 0 & 0.368 & 0.333 & 0.301 & 0.273 & 0.247 & 0.223 & 0.202 & 0.183 & 0.165 & 0.150 & 0.135 \\
\hline 1 & 0.736 & 0.699 & 0.663 & 0.627 & 0.592 & 0.558 & 0.525 & 0.493 & 0.463 & 0.434 & 0.406 \\
\hline 2 & 0.920 & 0.900 & 0.879 & 0.857 & 0.833 & 0.809 & 0.783 & 0.757 & 0.731 & 0.704 & 0.677 \\
\hline 3 & 0.981 & 0.974 & 0.996 & 0.957 & 0.946 & 0.934 & 0.921 & 0.907 & 0.891 & 0.875 & 0.875 \\
\hline 4 & 0.096 & 0.996 & 0.992 & 0.989 & 0.986 & 0.981 & 0.976 & 0.970 & 0.964 & 0.956 & 0.947 \\
\hline 5 & 0.999 & 0.999 & 0.998 & 0.998 & 0.997 & 0.996 & 0.994 & 0.992 & 0.990 & 0.987 & 0.983 \\
\hline 6 & 1.000 & 1.000 & & 1.000 & 0.999 & 0.999 & 0.999 & 0.998 & 0.997 & 0.997 & 0.995 \\
\hline 7 & & & & & 1.000 & 1.000 & 1.000 & 1.000 & 0.999 & 0.999 & 0.999 \\
\hline 8 & & & & & & & & & 1.000 & 1.000 & 1.000 \\
\hline
\end{tabular}

Figure 1: Poisson Distribution Table.

Example 2: Spare part category 1; $\mathrm{MAD}=1, \mathrm{D}_{\text {ann }}=2$, PL $=98 \%, \mathrm{D}_{r s t}=1.3$,

$\mathrm{D}_{\text {ann }} \geq \mathrm{MAD}$ - Spare part gets qualified as stocking spare part $\Rightarrow \mathrm{m}=1$;

$\mathrm{PL}(\mathrm{m}=1)=0.699=69.9 \%$ which is below $\mathrm{PL} \Rightarrow$ increment by 1

$\mathrm{PL}(\mathrm{m}=2)=0.900=90 \%$ which is below $\mathrm{PL} \Rightarrow$ increment by 1

$\mathrm{PL}(\mathrm{m}=3)=0.974=94.7 \%$ which is below $\mathrm{PL} \Rightarrow$ increment by 1

$\mathrm{PL}(\mathrm{m}=4)=0.966=99.6 \%$ which is above $\mathrm{PL} \Rightarrow \mathbf{m}=\mathbf{4}$.

Example 3: Same as example 2, but PLT $=1 \%$

PL $(m=3)=0.974=97.4 \%$ which is above PL-PLT $=97 \% \Rightarrow$ $\mathbf{m}=\mathbf{3}$

The tolerance reduces stocks by 1 spare part!

Example 4: Same as example 3, but $\mathrm{CRF}=100 \%$ and parts is considered as category 2

The $\mathrm{D}_{\text {rst }}$ calculation has to take this into account and need to be re-calculated.

The new $\mathrm{D}_{\text {rst }}=0.55$.

PL $(m=1)=0.894=89.4 \%$ which is below PL-PLT $\Rightarrow$ increment by 1

$\mathrm{PL}(\mathrm{m}=2)=0.982=98.2 \%$ which is above PL-PLT $\Rightarrow \mathbf{m}=\mathbf{2}$

The redundancy reduces stock by 2 spare parts!

Guideline how to use the Poisson Distribution Table (According to the above examples)

Whenever the companies It-situation allows it the above explains manual method to obtain the right stocking quantity the below described formula could be integrated and the entire process can be conducted automatically.

$$
P\{R \leq m\}=e^{-D_{r s t}} \times \sum_{0}^{m} \frac{\left(D_{r s t}\right)^{m}}{m}
$$

$P=$ Probability,

$R=$ number of removals

\section{Optimization of Stocks in Storehouses}

One major impact of the ongoing globalization for mid-size companies is the pressure to reduce cost where ever they can. The implementation of an automated end to end logistics solution was over the last decade only affordable by mostly global, big size companies. Today with the continuously developments in IT solution even small and midsize companies can benefit from such solutions. The aim for these companies should be to automate manual, time consuming processes as much as possible.

In all of the visited mid -size companies':

- The ordering of frequently used parts were done mostly manual,

- The control of the inventory is monitored by employees on daily or weekly routine checks,

- The follow up of ordered material and spare parts is done manual.

These are only three examples of time and cost intensive manual processes within their supply chain. In order to compete with sometimes global competitor's owner of mid-size companies are struggling with e.g. high salaries of their employees and the amount of people they have to employ to full fill these routine tasks. All of the interviewed mid-size companies owner confirmed that they are very much looking forward to any practical solution which would allow them to automate these processes and help them to reduce their fix costs. 

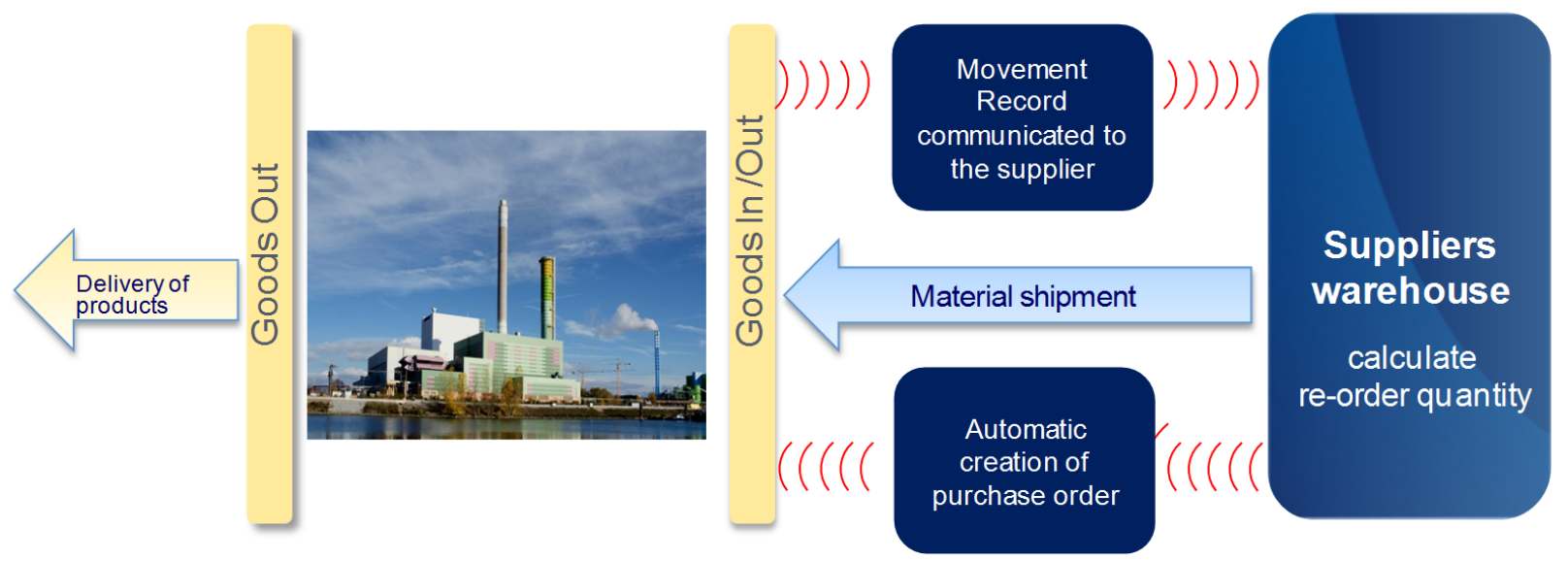

Figure 2: Process model of an It supported replenishment systemv.

With the availability of SAP based IT-solutions in the early 90s it was for the first time possible to think about automation of the supply chain. With the continuously development of advanced logistic solution from various suppliers it is meanwhile possible to connect different system with each other.

The huge cost saving potential of an automated replenishment process is that it actually allows companies to decrease their level of safety stock because the stock level is monitored automatically and therewith the response time and therewith replenishment time shrinks significantly. The result is simple, the stock safety level can be decreased and the investment in stocks therewith as well. Experience in the airline sector had proven that most of the customer could melt down their stockings of goods and raw material by sometimes more than $50 \%$. As also mid-size companies keep sometimes stockings worth Millions of Euro, a potential $50 \%$ onetime saving could have a huge impact on the survival of the company. Due to the melt down of the stock level, the one time savings are only one of its benefits. Also the time consuming reoccurring tasks of purchasing and controlling routine material are no longer needed as the It-system takes care of it.

The main challenge here is to establish a connection and exchange of simple xml-messages to the logistic system of the main supplier e.g. (as displayed below).

Once the connection is set up, the companies should think about which part numbers it makes sense to incorporate. The authors suggest to start only with parts which are quite frequently consumed and low value items. For high value material only consumed from time to time the experiences shows that these parts should be ordered manual as usual as it makes no sense to stock parts which are too valuable and eventually not consumed.

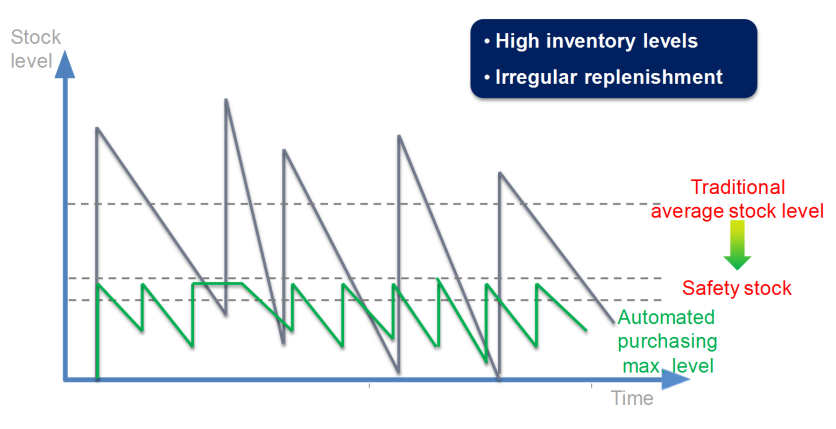

Figure 3: Comparison of traditional manual order cycles vs. an automated replenishment process

Depending on the nominated forwarder the lead time of the purchased parts an analysis of the right safety level can be conducted. The aim of this is to purchase only the quantity needed to maintain the production with a minimum of safety level on top to avoid falling in no stock situation.

Another advantage of an automated managed inventory is that most of the suppliers can guarantee their customer that they always will have enough material on side as the level of stocks it is electronically monitored by the supplier. All the manual efforts spend in avoiding any potential production stop due to non-availability of the required material are therewith history. Resources originally dedicated to watch the stock level could also be freed and used for different tasks.

Concrete benefits of an automated replenishment in mid-size companies:

1. Faster re-supplier time due to direct connection to the supplier $\Rightarrow$ lower invest in stockings;

2. Reoccurring, time-consuming tasks are automated. No manual purchasing anymore for the agreed part 
number range $\Rightarrow$ employees could be used for new tasks;

3. No longer risk of out of stocking due to IT-monitored stock level.

Certainly it is true that the efforts needed to spend on connecting different It- systems could be a huge challenge and shout of course not be underestimated but one it is successfully done the advantages will make it up. The necessary support on doing so shouldn't turn out as a problem. With the status of October 2011 even in Germany more than two thousand SAP-IT consultants were offering their help.

\section{Conclusion}

Considering the ongoing globalization are mainly small and medium-sized enterprises affected by the enormous pressure to reduce costs. The article explains the mathematical model for the Poisson distribution of the probability of determining the size of stocks and the calculation procedure shown in several examples. This method of calculating the size and range of stocks is used e.g. in the airline.

Acknowledgement: The contribution was created within the framework of the VEGA 1/0001/18 grant project.

\section{References}

[1] Radermacher, F.J. (2003). Globalisierung - Herausforderung für den Mittelstand, In. Schmeisser, W. Handbuch Unternehmensnachfolge, Stuttgart.

[2] Klein,S. (2003). Der strategische Wandel während des Nachfolgeprozesses im Familienunternehmen (pp. 23ff). In. Schmeisser u. a. (Hrsg.), Handbuch Unternehmensnachfolge, Stuttgart.

[3] Breuninger,H (1998). Psychologische Aspekte der Unternehmensnachfolge (Psychological aspects of corporate succession) (pp 49ff). In. Sobanski H.; Gutmann, J. (Hrsg.), Erfolgreiche Unternehmensnachfolge (Successful corporate succession), Wiesbaden.

[4] Gerke-Holzhäuer,F. (1996). Generationenwechsel. In. Familienunternehmen-Psychologische Aspekte des Führungswechsels, Wiesbaden.

[5] Fromm,R. et al. (2002). Die richtige Unternehmernachfolge im Mittelstand (The correct corporate succession), BBE-PraxisLeitfaden (BBE-Praxis Guide), Köln.

[6] Sobanski, H.(2008). Einführung und Konzeption des Buches (Introduction and conception of the book). In. Gutmann, J. Erfolgreiche Unternehmensnachfolge (Successful corporate succession), Wiesbaden.

[7] Möller, J.; Schödel, Ch.; Schödel, U.J.; Kulka, J. (2010). The meaning of knowledge transfer in terms of business succession. In. 6-th International Bata Conference, Zlín. ISBN 978-80-7318-9228.

[8] Möller, J.; Schödel, U. J.; Schödel, Ch.; Kulka, J. (2010). Facing business succession in technical mid-size companies. In. 6-th International Bata Conference, Zlín. ISBN 978-80-7318-922-8.

[9] Fedorko, G.; Molnar, V; Honus, S.; et al. (2018). The Application of Simulation Model of a Milk Run to Identify the Occurrence of Failures. International Journal of Simulation Modelling. 17(3), 444-457. 